\title{
Modal Analysis of Directional Coupler and Its Equivalent Circuit
}

\author{
Morteza Mohammadi ${ }^{1}$ \\ ${ }^{1}$ Department of Electrical Engineering, Shahid Sattari Aeronautical University of Science and Technology, Tehran, Iran \\ *corresponding author, E-mail: mor_mohammadi@elec.iust.ac.ir
}

\begin{abstract}
Modal analysis for the directional coupler is presented in this paper. The analysis is based on the mode-matching technique. The theory is verified by Ansoft HFSS software at a directional coupler with standard X-band (WR 90) rectangular waveguide ports. Element values of equivalent circuit model are computed by using the S-parameters obtained from the presented method in this paper. In addition, this paper has corrected two formulations used in two previous works which have been published.
\end{abstract}

\section{Introduction}

Duo to its equal power splitting, high isolation, low VSWR and accurate 90 phasing, the directional coupler [1] is a very attractive microwave circuit element for many applications such as in the duplexer, balance mixers, broad band-band switches, and H-plane magic tee[2,3].

The structure of a narrow wall directional coupler is shown in Fig. 1, the two waveguides are coupled through the slot in the narrow wall. The key to designing the coupler is to obtain the width of the slot and the width of the coupling region $[4,5]$, so a large number of directional coupler simulated to find out the best one which realizes a $-3 \mathrm{~dB}$ coupler. This process is a time-consuming course. Therefore fast computing method is needed to analyze the transmission characteristic of the directional coupler. This paper uses the mode-matching technique directly to design the directional coupler. The design method is based on the field expansion into the normalized incident and scattered waves [6]-[9]. The theory yields the modal S-matrix of the directional coupler directly.

There are a few works which have obtained equivalent circuit of the waveguide directional coupler with a large aperture. Hirako et al. proposed a new approach which uses a transformer to the equivalent circuit for this structure [10], but in this paper, capacity and inductor are used instead of the transformer. In this paper is presented an accurate circuit model for the structure. The topology of the model is the same as that introduced by Marcuvitz [11]. This method calculates the admittance matrix of the directional coupler from its scattering matrix that is obtained by the modematching technique.

\section{Design of the directional coupler}

\subsection{Modal analysis}

The geometry of the narrow wall directional coupler is shown in Fig. 1, the two waveguides are coupled through the slot in the narrow wall.

The directional coupler is decomposed into five regions (Fig. 1(b)), and discontinuity change only in waveguide width. The total scattering matrix of the directional coupler is formulated by suitable direct combination of the related individual modal scattering matrices.

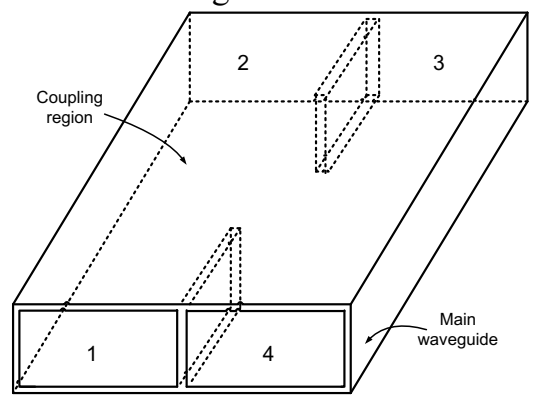

(a) 3-D structure

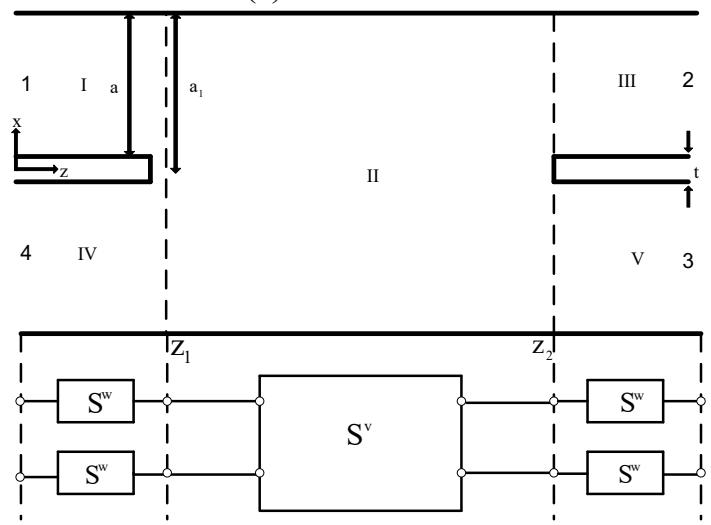

(b) Top view

Figure 1: Configuration of the directional coupler.

Because there is no $y$ variation introduced by this discontinuity, a $T E_{10}^{Z}$ wave incident in the main waveguide lexcites only $T E_{n 0}^{z}$ waves. Therefore, for each subregion $\mathrm{v}=$ I, II, III, IV, and V, the fields [12]: 


$$
\begin{array}{ll}
\mathrm{E}_{\mathrm{X}}=-\frac{1}{\varepsilon} \frac{\partial \phi^{\mathrm{TE}}}{\partial \mathrm{y}} & \mathrm{H}_{\mathrm{x}}=-\mathrm{j} \frac{1}{\omega \mu \varepsilon} \frac{\partial^{2} \phi^{\mathrm{TE}}}{\partial \mathrm{x} \partial \mathrm{z}} \\
\mathrm{E}_{\mathrm{y}}=\frac{1}{\varepsilon} \frac{\partial \phi^{\mathrm{TE}}}{\partial \mathrm{x}} & \mathrm{H}_{\mathrm{y}}=-\mathrm{j} \frac{1}{\omega \mu \varepsilon} \frac{\partial^{2} \phi^{\mathrm{TE}}}{\partial \mathrm{y} \partial \mathrm{z}} \\
\mathrm{E}_{\mathrm{z}}=0 & \mathrm{H}_{\mathrm{z}}=-\mathrm{j} \frac{1}{\omega \mu \varepsilon}\left(\frac{\partial^{2}}{\partial \mathrm{z}^{2}}+\omega^{2} \mu \varepsilon\right) \phi^{\mathrm{TE}^{\mathrm{z}}}
\end{array}
$$

Are derived from the $\mathrm{z}$ component of the Hertzian vector potential $\varphi^{T E^{Z}}$, which is assumed to be a sum of suitably normalized eigenmodes satisfying the corresponding boundary conditions:

$$
\begin{aligned}
& \phi^{\mathrm{I}}=\phi^{\mathrm{TE}}+\phi^{\mathrm{TE}}= \\
& \cos \left(\frac{\pi}{\mathrm{a}}\left(\mathrm{x}-\frac{\mathrm{t}}{2}\right)\right) \mathrm{e}^{-j \beta_{10} \mathrm{z}} \quad \mathrm{z} \leq \mathrm{z}_{1}, \frac{\mathrm{t}}{2} \leq \mathrm{x} \leq \mathrm{a}_{1} \quad(2-\mathrm{a}) \\
& +\sum_{\mathrm{m}=1}^{\infty} \mathrm{A}_{\mathrm{m}}^{\mathrm{I}} \cos \left(\frac{\mathrm{m} \pi}{\mathrm{a}}\left(\mathrm{x}-\frac{\mathrm{t}}{2}\right)\right) \mathrm{e}^{\mathrm{j} \beta_{\mathrm{m} 0}^{\mathrm{I} z}} \\
& \phi^{\mathrm{II}}=\sum_{\mathrm{m}=1}^{\infty}\left(\mathrm{C}_{\mathrm{m}} \mathrm{e}^{-\mathrm{j} \beta_{\mathrm{m} 0}^{\mathrm{II}} \mathrm{z}}+\mathrm{D}_{\mathrm{m}} \mathrm{e}^{\left.\mathrm{j} \beta_{\mathrm{m} 0}^{\mathrm{II}}\right)}\right. \\
& \cos \left(\frac{\mathrm{m} \pi}{2 \mathrm{a}_{1}}\left(\mathrm{x}+\mathrm{a}_{1}\right)\right) \\
& \phi^{\mathrm{III}}=\sum_{\mathrm{m}=1}^{\infty} \mathrm{A}_{\mathrm{m}}^{\mathrm{III}} \cos \left(\frac{\mathrm{m} \pi}{\mathrm{a}}\left(\mathrm{x}-\frac{\mathrm{t}}{2}\right)\right) \mathrm{e}^{-\mathrm{j} \beta_{\mathrm{m} 0}^{\mathrm{III}} \mathrm{z}} \quad \mathrm{z}_{1} \leq \mathrm{z} \leq \mathrm{z}_{2},|\mathrm{x}| \leq \mathrm{a}_{1} \quad(2-\mathrm{c}) \mathrm{z}_{2},|\mathrm{x}| \leq \mathrm{a}_{1} \quad(2-\mathrm{b}) \\
& \phi^{\mathrm{IV}}=\sum_{\mathrm{m}=1}^{\infty} \mathrm{A}_{\mathrm{m}}^{\mathrm{IV}} \cos \left(\frac{\mathrm{m} \pi}{\mathrm{a}}\left(\mathrm{x}+\frac{\mathrm{t}}{2}\right)\right) \mathrm{e}^{\mathrm{j} \beta_{\mathrm{m} 0}^{\mathrm{IV}} \mathrm{z}} \quad \mathrm{z} \leq \mathrm{z}_{1},-\frac{\mathrm{t}}{2} \leq \mathrm{x} \leq-\mathrm{a}_{1}(2-\mathrm{c}) \\
& \phi^{\mathrm{V}}=\sum_{\mathrm{m}=1}^{\infty} \mathrm{A}_{\mathrm{m}}^{\mathrm{V}} \cos \left(\frac{\mathrm{m} \pi}{\mathrm{a}}\left(\mathrm{x}+\frac{\mathrm{t}}{2}\right)\right) \mathrm{e}^{-\mathrm{j} \beta_{\mathrm{m} 0}^{\mathrm{V} \mathrm{z}}} \quad \mathrm{z} \geq \mathrm{z}_{2},-\frac{\mathrm{t}}{2} \leq \mathrm{x} \leq-\mathrm{a}_{1}(2-\mathrm{c})
\end{aligned}
$$

where

$$
\begin{aligned}
& \beta_{\mathrm{m} 0}^{\mathrm{V}}=\beta_{\mathrm{m} 0}^{\mathrm{IV}}=\beta_{\mathrm{m} 0}^{\mathrm{III}}=\beta_{\mathrm{m} 0}^{\mathrm{I}}=\left\{\begin{array}{cc}
\sqrt{\omega^{2} \mu \varepsilon-\left(\frac{\mathrm{m} \pi}{\mathrm{a}}\right)^{2}} & \beta>\frac{\mathrm{m} \pi}{\mathrm{a}} \\
0 & \beta=\frac{\mathrm{m} \pi}{\mathrm{a}} \\
-\sqrt{\omega^{2} \mu \varepsilon-\left(\frac{\mathrm{m} \pi}{\mathrm{a}}\right)^{2}} & \beta<\frac{\mathrm{m} \pi}{\mathrm{a}}
\end{array}\right. \\
& \beta_{\mathrm{m} 0}^{\mathrm{II}}=\left\{\begin{array}{cc}
\sqrt{\omega^{2} \mu \varepsilon-\left(\frac{\mathrm{m} \pi}{2 \mathrm{a}_{1}}\right)^{2}} & \beta>\frac{\mathrm{m} \pi}{2 \mathrm{a}_{1}} \\
0 & \beta=\frac{\mathrm{m} \pi}{2 \mathrm{a}_{1}} \\
-\sqrt{\omega^{2} \mu \varepsilon-\left(\frac{\mathrm{m} \pi}{2 \mathrm{a}_{1}}\right)^{2}} & \beta<\frac{\mathrm{m} \pi}{2 \mathrm{a}_{1}}
\end{array}\right.
\end{aligned}
$$

$A_{m}^{I}, D_{m}^{I I}$ and $A_{m}^{I V}$ are the unknown amplitude coefficient of the reflected $T E_{n 0}^{Z}$ modes in waveguides 1, 2, and 4, respectively. Also, $A_{m}^{I I I}, C_{m}^{I I}$ and $A_{m}^{V}$ are the unknown amplitude coefficient of the transmitted $T E_{n 0}^{Z}$ modes in waveguides 3,2 , and 5 , respectively.

In the references [8] and [9], authors have used negative coefficient for $\frac{t}{2}$ in $(2-\mathrm{a}, \mathrm{c})$ and $(1-\mathrm{a})$ in the cases $\mathrm{p}=\mathrm{II}$ and $\mathrm{V}$, respectively. By using formulations, boundary conditions at $x=-\frac{t}{2}$ and $x=-a_{1}$ would not be satisfied. In this paper, has shown in the equations (2-d) and (2-e), coefficient of $\frac{t}{2}$ has been changed from negative to positive.

The field expansion equations obtained from (1) and (2) in subregions 1, 2 and 4 are:

$$
\begin{aligned}
& \mathrm{E}_{\mathrm{y}}^{\mathrm{I}}=-\frac{1}{\varepsilon} \frac{\pi}{\mathrm{a}}\left[\sin \left(\frac{\pi}{\mathrm{a}}\left(\mathrm{x}-\frac{\mathrm{t}}{2}\right)\right) \mathrm{e}^{-\mathrm{j} \beta_{10} \mathrm{z}}\right. \\
& \left.+\sum_{m=1}^{\infty} m A_{m}^{I} \sin \left(\frac{m \pi}{a}\left(x-\frac{t}{2}\right)\right) e^{j \beta_{m 0}^{I} z}\right] \\
& \mathrm{H}_{\mathrm{x}}^{\mathrm{I}}=\frac{1}{\omega \mu \varepsilon} \frac{\pi}{\mathrm{a}}\left[\beta_{10} \sin \left(\frac{\pi}{\mathrm{a}}\left(\mathrm{x}-\frac{\mathrm{t}}{2}\right)\right) \mathrm{e}^{-\mathrm{j} \beta_{10} \mathrm{z}}\right. \\
& \left.-\sum_{m=1}^{\infty} m \beta_{m 0}^{I} A_{m}^{I} \sin \left(\frac{m \pi}{a}\left(x-\frac{t}{2}\right)\right) e^{j \beta_{m 0}^{I} z}\right] \\
& \mathrm{E}_{\mathrm{y}}^{\mathrm{II}}=-\frac{1}{\varepsilon} \frac{\pi}{2 \mathrm{a}_{1}} \sum_{\mathrm{m}=1}^{\infty} \mathrm{m}\left(\mathrm{C}_{\mathrm{m}} \mathrm{e}^{-\mathrm{j} \beta_{\mathrm{m} 0}^{\mathrm{II}} \mathrm{z}}+\mathrm{D}_{\mathrm{m}} \mathrm{e}^{\mathrm{j} \beta_{\mathrm{m} 0}^{\mathrm{II}} \mathrm{z}}\right) \\
& \sin \left(\frac{m \pi}{2 a_{1}}\left(x+a_{1}\right)\right) \\
& \mathrm{H}_{\mathrm{x}}^{\mathrm{II}}=\frac{1}{\omega \mu \varepsilon} \frac{\pi}{2 \mathrm{a}_{1}} \sum_{\mathrm{m}=1}^{\infty} \mathrm{m} \beta_{\mathrm{m} 0}^{\mathrm{II}}\left(\mathrm{C}_{\mathrm{m}} \mathrm{e}^{-\mathrm{j} \beta_{\mathrm{m} 0}^{\mathrm{II}} \mathrm{z}}-\mathrm{D}_{\mathrm{m}} \mathrm{e}^{\mathrm{j} \beta_{\mathrm{m} 0}^{\mathrm{II}} \mathrm{z}}\right) \\
& \sin \left(\frac{m \pi}{2 a_{1}}\left(x+a_{1}\right)\right) \\
& \mathrm{E}_{\mathrm{y}}^{\mathrm{IV}}=-\frac{1}{\varepsilon} \frac{\pi}{\mathrm{a}}\left[\sum_{\mathrm{m}=1}^{\infty} \mathrm{mA} \mathrm{m}_{\mathrm{m}}^{\mathrm{IV}} \sin \left(\frac{\mathrm{m} \pi}{\mathrm{a}}\left(\mathrm{x}+\frac{\mathrm{t}}{2}\right)\right) \mathrm{e}^{\mathrm{j} \beta_{\mathrm{m} 0}^{\mathrm{I}} \mathrm{z}}\right] \\
& \mathrm{H}_{\mathrm{x}}^{\mathrm{IV}}=-\frac{1}{\omega \mu \varepsilon} \frac{\pi}{\mathrm{a}}\left[\sum_{\mathrm{m}=1}^{\infty} \mathrm{m} \beta_{\mathrm{m} 0}^{\mathrm{I}} \mathrm{A}_{\mathrm{m}}^{\mathrm{IV}} \sin \left(\frac{\mathrm{m} \pi}{\mathrm{a}}\left(\mathrm{x}+\frac{\mathrm{t}}{2}\right)\right) \mathrm{e}^{\mathrm{j} \beta_{\mathrm{m} 0}^{\mathrm{I} z}}\right]
\end{aligned}
$$

Matching of the tangential field components at $\mathrm{z}=\mathrm{Z} 1$ are:

$$
\begin{array}{lc}
\mathrm{E}_{\mathrm{y}}^{\mathrm{II}}=\left\{\begin{array}{cc}
\left.\mathrm{E}_{\mathrm{y}}^{\mathrm{I}, \mathrm{IV}}\right|_{\mathrm{z}=\mathrm{z}_{1}} & \frac{\mathrm{t}}{2} \leq|\mathrm{x}| \leq \mathrm{a}_{1} \\
0 & |\mathrm{x}| \leq \frac{\mathrm{t}}{2}
\end{array}\right. \\
\mathrm{H}_{\mathrm{X}}^{\mathrm{II}}=\left.\mathrm{H}_{\mathrm{X}}^{\mathrm{I}, \mathrm{IV}}\right|_{\mathrm{z}=\mathrm{z}_{1}} & \frac{\mathrm{t}}{2} \leq|\mathrm{x}| \leq \mathrm{a}_{1}
\end{array}
$$

Multiply (6-a) with $\sin \left(\frac{n \pi}{2 a_{1}}\left(x+a_{1}\right)\right)$ integrate the equation $\operatorname{over}\left(-\mathrm{a}_{1}, \mathrm{a}_{1}\right)$, we get(for simplify $\left.\mathrm{z}=\mathrm{Z}_{1}=0\right)$ :

$$
\begin{aligned}
& \frac{1}{2} \mathrm{n}\left(\mathrm{C}_{\mathrm{n}}+\mathrm{D}_{\mathrm{n}}\right)= \\
& \frac{1}{\mathrm{a}}\left[\sum_{\mathrm{m}=1}^{\mathrm{K}} \mathrm{mA}_{\mathrm{m}}^{\mathrm{IV}} \mathrm{H}_{\mathrm{nm}}+\overline{\mathrm{H}}_{\mathrm{n} 1}+\sum_{\mathrm{m}=1}^{\mathrm{L}} \mathrm{mA}_{\mathrm{m}}^{\mathrm{I}} \overline{\mathrm{H}}_{\mathrm{nm}}\right]
\end{aligned}
$$

where

$$
\begin{aligned}
& \mathrm{H}_{\mathrm{nm}}=\int_{-\mathrm{a}_{1}}^{-\frac{\mathrm{t}}{2}} \sin \left(\frac{\mathrm{n} \pi}{2 \mathrm{a}_{1}}\left(\mathrm{x}+\mathrm{a}_{1}\right)\right) \sin \left(\frac{\mathrm{m} \pi}{\mathrm{a}}\left(\mathrm{x}+\frac{\mathrm{t}}{2}\right)\right) \mathrm{dx} \\
& \overline{\mathrm{H}}_{\mathrm{nm}}=\int_{\frac{\mathrm{t}}{2}}^{\mathrm{a}_{1}} \sin \left(\frac{\mathrm{n} \pi}{2 \mathrm{a}_{1}}\left(\mathrm{x}+\mathrm{a}_{1}\right)\right) \sin \left(\frac{\mathrm{m} \pi}{\mathrm{a}}\left(\mathrm{x}-\frac{\mathrm{t}}{2}\right)\right) \mathrm{dx}
\end{aligned}
$$

Multiply (6-b) with $\sin \left(\frac{n \pi}{a}\left(x+\frac{t}{2}\right)\right)$ and $\sin \left(\frac{n \pi}{a}\left(x-\frac{t}{2}\right)\right)$ integrate the equation over $\left(-a_{1},-\frac{t}{2}\right)$ and $\left(\frac{t}{2}, a_{1}\right)$, respectively we get: 
$\frac{1}{\mathrm{a}_{1}} \sum_{\mathrm{m}=1}^{\mathrm{K}} \mathrm{m} \beta_{\mathrm{m} 0}^{\mathrm{II}}\left(\mathrm{C}_{\mathrm{m}}-\mathrm{D}_{\mathrm{m}}\right) \mathrm{H}_{\mathrm{mn}}=-\mathrm{n} \beta_{\mathrm{n} 0}^{\mathrm{I}} \mathrm{A}_{\mathrm{n}}^{\mathrm{IV}}$

$\frac{1}{\mathrm{a}_{1}} \sum_{\mathrm{m}=1}^{\mathrm{L}} \mathrm{m} \beta_{\mathrm{m} 0}^{\mathrm{II}}\left(\mathrm{C}_{\mathrm{m}}-\mathrm{D}_{\mathrm{m}}\right) \overline{\mathrm{H}}_{\mathrm{mn}}=\beta_{10} \delta_{\mathrm{n} 1}-\mathrm{n} \beta_{\mathrm{n} 0}^{\mathrm{I}} \mathrm{A}_{\mathrm{n}}^{\mathrm{I}}$

When the same procedure is done at $\mathrm{z}=\mathrm{Z}_{2}$, equations (10)(12) will be obtain:

$\frac{1}{2} \mathrm{n}\left(\mathrm{C}_{\mathrm{n}} \mathrm{e}^{-\mathrm{j} \beta_{\mathrm{n} 0}^{\mathrm{II}} \mathrm{z}_{2}}+\mathrm{D}_{\mathrm{n}} \mathrm{e}^{\mathrm{j} \beta_{\mathrm{n} 0}^{\mathrm{II}} \mathrm{z}_{2}}\right)=$

$\frac{1}{\mathrm{a}}\left[\sum_{\mathrm{m}=1}^{\mathrm{K}} \mathrm{mA}_{\mathrm{m}}^{\mathrm{V}} \mathrm{e}^{-\mathrm{j} \beta_{\mathrm{m} 0}^{\mathrm{I}} \mathrm{z}_{2}} \mathrm{H}_{\mathrm{nm}}+\sum_{\mathrm{m}=1}^{\mathrm{L}} \mathrm{mA}_{\mathrm{m}}^{\mathrm{III}} \mathrm{e}^{-\mathrm{j} \beta_{\mathrm{m} 0}^{\mathrm{I}} \mathrm{z}_{2}} \overline{\mathrm{H}}_{\mathrm{nm}}\right]$

$\frac{1}{\mathrm{a}_{1}} \sum_{\mathrm{m}=1}^{\mathrm{K}} \mathrm{m} \beta_{\mathrm{m} 0}^{\mathrm{II}}\left(\mathrm{C}_{\mathrm{m}} \mathrm{e}^{-\mathrm{j} \beta_{\mathrm{m} 0}^{\mathrm{II}} \mathrm{z}_{2}}-\mathrm{D}_{\mathrm{m}} \mathrm{e}^{\mathrm{j} \beta_{\mathrm{m} 0}^{\mathrm{II}}}\right) \mathrm{H}_{\mathrm{mn}}=$

$\mathrm{n} \beta_{\mathrm{n} 0}^{\mathrm{I}} \mathrm{A}_{\mathrm{n}}^{\mathrm{V}} \mathrm{e}^{-\mathrm{j} \beta_{\mathrm{n} 0}^{\mathrm{I}} \mathrm{z}_{2}}$

$\frac{1}{\mathrm{a}_{1}} \sum_{\mathrm{m}=1}^{\mathrm{L}} \mathrm{m} \beta_{\mathrm{m} 0}^{\mathrm{II}}\left(\mathrm{C}_{\mathrm{m}} \mathrm{e}^{-\mathrm{j} \beta_{\mathrm{m} 0}^{\mathrm{II}} \mathrm{z}_{2}}-\mathrm{D}_{\mathrm{m}} \mathrm{e}^{\mathrm{j} \beta_{\mathrm{m} 0}^{\mathrm{II}} \mathrm{z}_{2}}\right) \overline{\mathrm{H}}_{\mathrm{mn}}=$

$\mathrm{n} \beta_{\mathrm{n} 0}^{\mathrm{I}} \mathrm{A}_{\mathrm{n}}^{\mathrm{III}} \mathrm{e}^{-\mathrm{j} \beta_{\mathrm{n} 0}^{\mathrm{I}} \mathrm{z}_{2}}$

In all of the above relations, $\mathrm{n}=1,2, \ldots \mathrm{N}$.

By solving equations (7)-(12) for $\mathrm{N}=\mathrm{K}=\mathrm{L}$ using Matlab software, the amplitudes of modes are obtained. Scattering matrix $\mathrm{S}^{\mathrm{c}}$ can be obtained by using the method proposed in [8] according to the amplitude of modes. Then the overall scattering matrix can be obtained by the direct combination of all the local scattering matrixes $S^{c}$ and $S^{w}$. Where $S^{w}$ is the scattering matrix of waveguide I, III, IV and V, and can be written as:

$\mathrm{S}^{\mathrm{W}}=\operatorname{Diag}\left[\mathrm{e}^{-\mathrm{j} \beta_{\mathrm{n} 0} \mathrm{~L}}\right]$

where $\mathrm{L}$ is the distance of discontinuity to the port of waveguide.

\subsection{Numerical results}

For the verification of the theory, the scattering parameters of the directional coupler with the parameters of $\mathrm{a}=22.9 \mathrm{~mm}$, $\mathrm{t}=1 \mathrm{~mm}$, and $\mathrm{z}_{2}-\mathrm{Z}_{1}=36 \mathrm{~mm}$ are calculated and compared with Ansoft HFSS software (Fig. 2). The results agree well with that obtained by MMM (mode-matching method) in this paper. According to the obtained results, there is a good convergence for $\mathrm{N}=4$ with 0.3 percent error. Phase characteristic of the directional coupler is shown in Fig. 3 that confirm the precise of $90^{\circ}$ phasing.

\section{Equivalent circuit}

The circuit model of the directional coupler with admittance parameters is shown in Fig. 4. For deriving an equivalentcircuit representation, the admittance matrix (Y) of the structure under consideration is computed by:

$[\mathrm{Y}]=\left[\mathrm{Y}_{0}\right]^{1 / 2} \cdot[\overline{\mathrm{Y}}] \cdot\left[\mathrm{Y}_{0}\right]^{1 / 2}$

with the normalized admittance matrix:

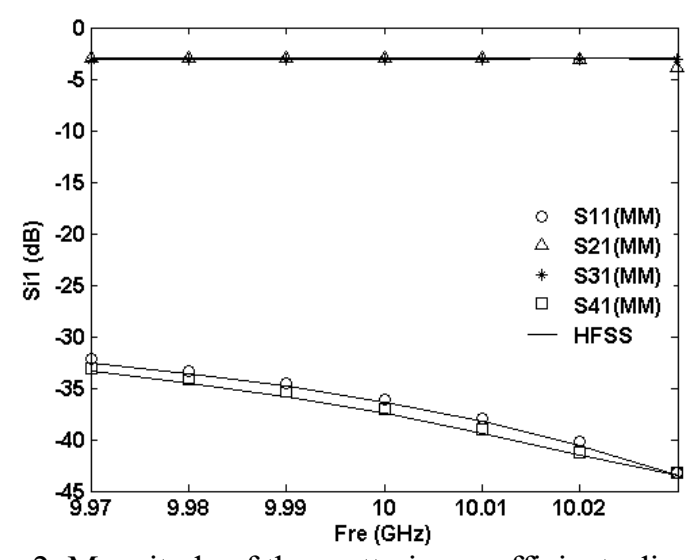

Figure 2. Magnitude of the scattering coefficients directional coupler.

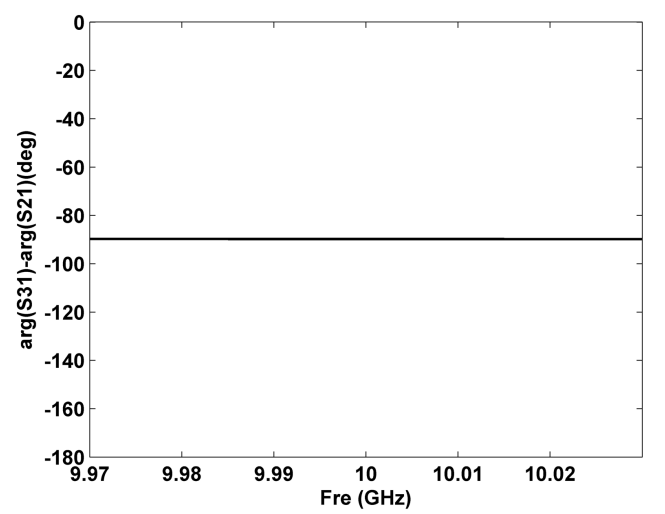

Figure 3. Phase characteristic of the designed directional coupler.

$[\overline{\mathrm{Y}}]=([\mathrm{I}]-[\mathrm{S}]) \times([\mathrm{I}]+[\mathrm{S}])^{-1}$

$[\mathrm{S}]$ is the related scattering matrix of the directional coupler computed by the MMM; [I] is the unit matrix; and $\left[\mathrm{Y}_{0}\right]$ is a square block diagonal matrix:

$\left[\mathrm{Y}_{0}\right]=\left[\begin{array}{cccc}\mathrm{Y}_{0}^{\mathrm{I}} & 0 & 0 & 0 \\ 0 & \mathrm{Y}_{0}^{\mathrm{III}} & 0 & 0 \\ 0 & 0 & \mathrm{Y}_{0}^{\mathrm{V}} & 0 \\ 0 & 0 & 0 & \mathrm{Y}_{0}^{\mathrm{IV}}\end{array}\right]$

where the elements of the $Y_{0}^{i}(\mathrm{i}=\mathrm{I}, \mathrm{III}, \mathrm{V}$,IV) diagonal matrices are:

$\mathrm{Y}_{0}^{\mathrm{i}}(\mathrm{n}, \mathrm{n})=\mathrm{Y}_{\mathrm{n}}^{\mathrm{i}}=\frac{\beta_{\mathrm{n}}^{\mathrm{i}}}{\omega \mu}$

The element values of the equivalent circuit in Fig. 4 are:

$\mathrm{Y}_{\mathrm{a}}=2\left(\mathrm{Y}_{11}-\mathrm{Y}_{12}\right)=2\left(\mathrm{Y}_{13}-\mathrm{Y}_{14}\right)$

$\mathrm{Y}_{\mathrm{b}}=2\left(\mathrm{Y}_{12}-\mathrm{Y}_{13}\right)=2\left(\mathrm{Y}_{34}-\mathrm{Y}_{13}\right)$

Fig. 5 indicates the circuit element values obtained from the MM solutions, while at Fig. 5: $G_{a}=\operatorname{Real}\left(Y_{a}\right), B_{a}=\operatorname{Image}\left(Y_{a}\right)$, $\mathrm{G}_{\mathrm{b}}=\operatorname{Real}\left(\mathrm{Y}_{\mathrm{b}}\right)$, and $\mathrm{B}_{\mathrm{b}}=\operatorname{Image}\left(\mathrm{Y}_{\mathrm{b}}\right)$. 


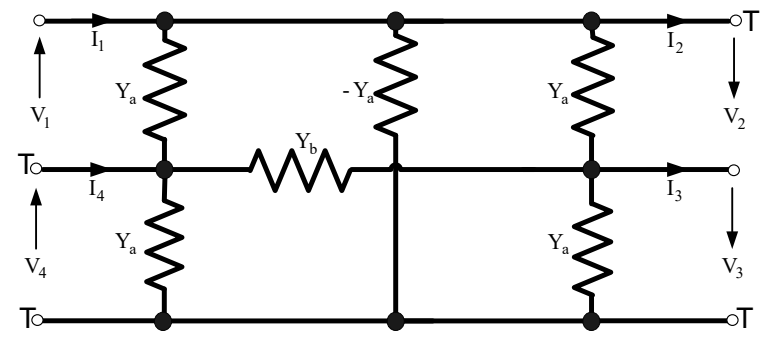

Figure 4. The equivalent circuit for the directional coupler with admittance parameters

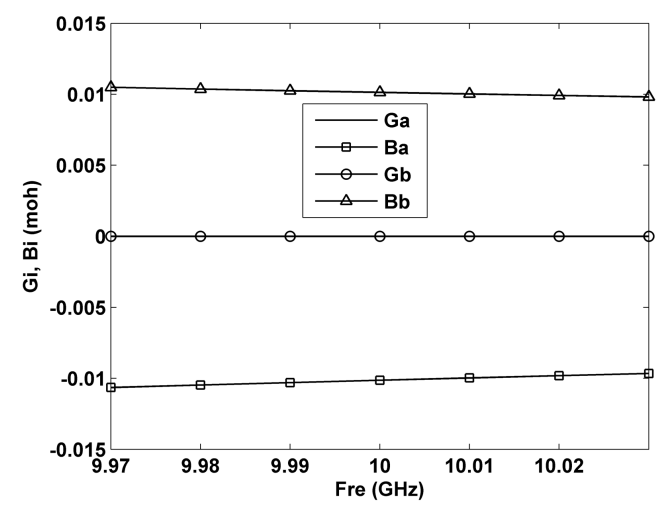

Figure 5. The equivalent circuit parameters for directional coupler with $\mathrm{a}=22.9 \mathrm{~mm}, \mathrm{t}=1 \mathrm{~mm}$ and $\mathrm{z}_{2}-\mathrm{Z}_{1}=36 \mathrm{~mm}$.

The circuit model of the directional coupler with lumped elements is shown in Fig. 6. Magnitudes of the elements have been shown in Figures 7 and 8.

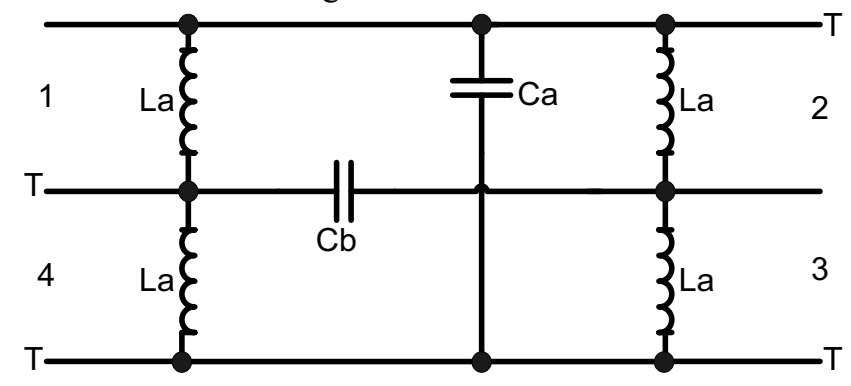

Figure 6. The equivalent circuit for the directional coupler with lumped elements

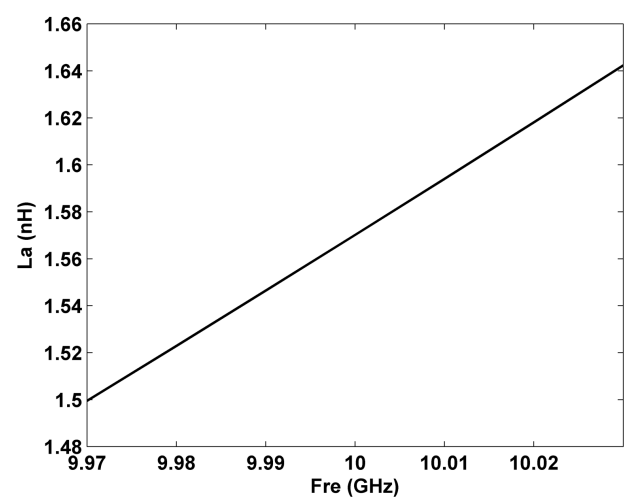

Figure 7. The equivalent inductance of the directional coupler

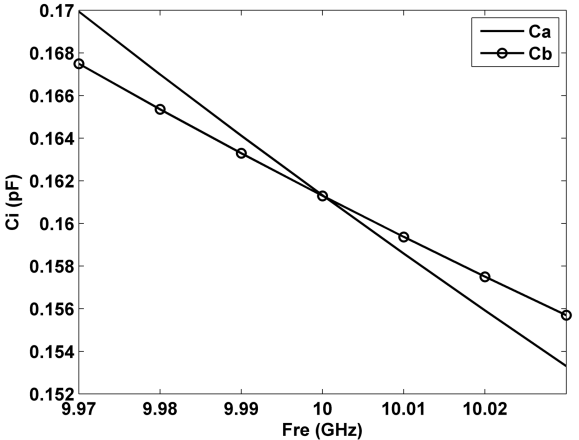

Figure 8. The equivalent Capacities of the directional coupler

\section{Conclusion}

A mode-matching method is presented to the modal analysis of the directional coupler. The explained theory is confirmed at scattering parameters of the directional coupler by HFSS software. Furthermore, in this paper, a novel equivalent circuit was presented that its element values are computed by using the S-parameters obtained from the presented method in this paper.

\section{References}

[1] Hildebrand, L. T., "Results for a simple compact narrow-wall directional coupler," IEEE Microwave and Guided Wave Letters, Vol. 10, No. 6, 231-232, June 2000.

[2] M. Mohammadi and F. H. Kashani "Planar eight port waveguide mono-pulse comparator" Progress In Electromagnetics Research C, Vol. 6, 103-113, 2009.

[3] M. Mohammadi, F. H. Kashani and J. Ghalibafan, "A compact planar monopulse combining network at Wband" 5th IEEE GCC Conference \& Exhibition, Kuwait City, pp. 1-5, 2009.

[4] Rizzi, P. A., Microwave Engineering Passive Circuits, Prentice Hall, Englewood Cliffs, NJ, 1988.

[5] Wang, Z.-X., W.-B. Dou, and Z.-L. Mei, "A compact H-plane magic tee designed at W band," Progress In Electromagnetics Research B, Vol. 5, 35-48, 2008.

[6] Riabi,M. L.,R. Thabet,and M. Belmeguenai,"Rigorous design and efficient optimization of quarter-wave transformers in metallic circular waveguides using the mode-matching method and the genetic algorithm," Progress In Electromagnetics Research, PIER 68,1533,2007.

[7] Huang, R. and D. Zhang, “Application of mode matching method to analysis of axisymmetric coaxial discontinuity structures used in permeability and/or permittivity measurement," Progress In Electromagnetics Research,PIER 67,205-230,2007.

[8] Z.X. Wang and W.B. Dou, A Design of Magic Tee with Coplanar Arms, International Journal of Infrared and Millimeter Waves, Vol. 25, NO.6, 939-958, June 2004.

[9] Z.X. Wang, W.B. Dou and G.H. Li, "A Design of HPlane Magic Tee at W Band" International Conference 
on Microwave and Millimeter Wave Technology, Vol 1, 280 - 283, April 2008.

[10] Hirako and Hsu "Equivalent network for H-plane rectangular-waveguide circuits and its practical application for analysis of circuit performance and field behavior" International Journal of RF and Microwave Computer-Aided Engineering, Vol 14 , No 3, 210 226, May 2004.

[11]N. Marcuvitz, Waveguide Handbook, Radiation Laboratory Series, vol. 10, New York, McGraw-Hill, 1951.

[12]A. Balanis, Advanced Engineering Electromagnetics, John Wiley and Sons, 1989.

[13] Pozar, D. M., Microwave Engineering, AddisonWesley, Reading MA, 1990. 